\title{
Experimental mass-flux measurements: a comparison of different gauges with estimated theoretical data
}

\author{
D. Font, ${ }^{1}$ M. Mases,${ }^{2}$ J. M. Vilaplana ${ }^{1}$ \\ ${ }^{1}$ Departament de Geología Dinàmica, Geofísica i Paleontologia, Universitat de Barcelona, 08071 Barcelona, Spain \\ ${ }^{2}$ ICC, Servei Geològic de Catalunya, Parc de Montjuic s/n, 08038 Barcelona, Spain
}

\begin{abstract}
In experimental snowdrifting mass-flux measurements many different instruments have been tested (Takeuchi, CEMAGREF, Mases, etc.). Very often the results obtained are a function of the gauge used. However, in order to compare data from different instruments, orders of magnitude have to be similar.

Since 1992, snowdrifting has been studied at an experimental plot at La Molina ski resort (eastern Spanish Pyrenees). The alpine site, characterized by a plateau topography, is located at $2250 \mathrm{~m}$.

In this paper, different gauges used to measure snowdrifting mass flux at this site are presented: one snow-collector column and two types of snow traps. Snow-collector columns (prismatic boxes) are permanent installations and are used to measure the massflux episode. Snow traps (Takeuchi, 1980; modified) are lighter and more mobile, and they are used for short experiments during a wind episode during which mass-flux data are obtained.

The three different gauges are compared and the rate of trapping efficiency is suggested from a comparison of the field data with estimated mass-flux data deduced from empirical formulae (Mellor and Fellers, 1986; Naaim-Bouvet and others, 1996). The massflux values obtained at the experimental site are lower than the estimated values.
\end{abstract}

\section{INTRODUGTION}

Wind-blown snow is one of the main causes of avalanches, which can lead to great economic losses in high-mountain areas (ski and mountain resorts). Snowdrifting also causes disturbance to traffic and is the main reason for closing roads in mountain areas during the winter.

Snowdrifting is very similar to aeolian sand transport. Thus, basic aeolian sand-transport studies (Bagnold, 1941) are classically applied to snow transport. However, there are differences between the behaviour of sand and snow grains during scour, transport and sedimentation, mainly due to the differences in cohesion between the grains.

The aim of this paper is to compare three different field gauges used to quantify the snowdrifting mass flux at different heights. One of them, a snow-collector column, is stationary, so it quantifies the snowdrifting in a total wind episode. The other gauges are used in short measuring experiments during a wind episode. The data used in this work were collected during four winters: 1992-93, 1993-94, 199495 and 1995-96.

\section{THE STUDY AREA}

The experimental site is located on the highest slopes of $\mathrm{La}$ Molina ski resort (Mases and Vilaplana, 1994).

The landscape in the study area is divided into two parts. In the lower part, there are steeper slopes while the higher part is characterized by high erosion surfaces or platforms and is flatter. However, there are some slope ruptures that produce snowdrifts. The study was undertaken in the higher part.

The altitude ranges between 2000 and $2400 \mathrm{~m}$ a.s.l., with a slope mainly exposed to the north. Mean annual precipitation is about $1211.2 \mathrm{~mm}$ of water; mean annual solid precipitation is about $414 \mathrm{~mm}$ of water and the average snow-accumulation thickness is about $2.5 \mathrm{~m}$ at $2050 \mathrm{~m}$ a.s. 1 . (Salvador, 1985). Precipitation comes mainly from the east, and is often followed by strong northerly winds that immediately redistribute all the fresh snow.

\section{EXPERIMENTAL EQUIPMENT AND FIELD METHODS}

The experimental site is equipped with several gauges that allow us to characterize the wind episodes.

Wind-vane and wind-speed sensor connected to a data logger

The sensor is situated $11 \mathrm{~m}$ above the terrain surface, at the top of a skilift pylon. This anemographic station provides a continuous record during the snow season (approximately 7 months) of the average wind speed and direction, with a sampling time of 20 seconds and a logging time of 2 minutes.

\section{Snow collector columns}

The snow is collected through a frontal horizontal inlet tube of $1.54 \mathrm{~cm}^{2}$ and the air escapes through a rear aperture of $12.5 \mathrm{~cm}^{2}$. Inside the collectors there are three baffles that re- 


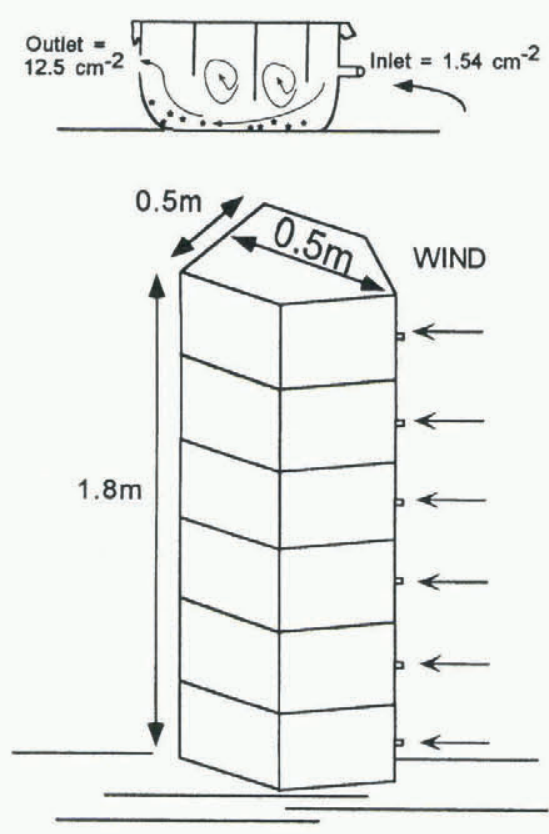

SNOW COLLECTOR COLUMNS

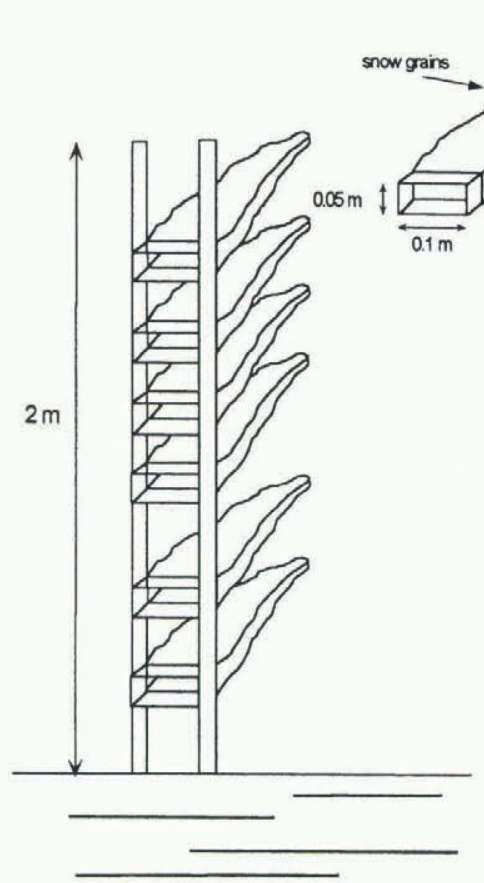

A SNOW TRAPS

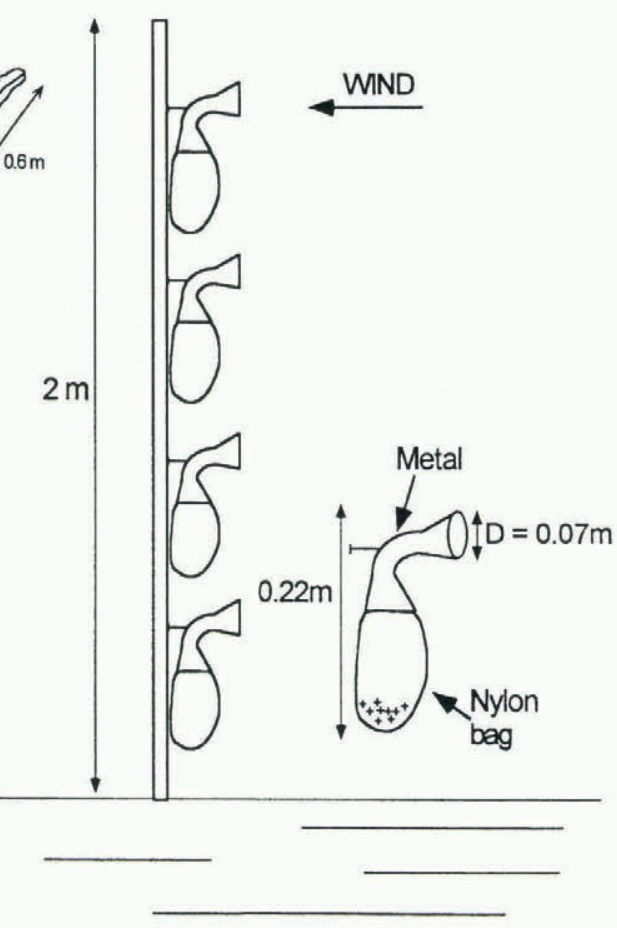

B SNOW TRAPS

Fig. 1. The drifting-snow gauges.

duce the flux speed and facilitate the deposition of the transported particles. The capacity of the collectors is 401 (Fig. 1).

There are two columns of six collectors (boxes) each, one column facing north and the other facing northwest, as these are the two main wind directions. The snow-collector columns remain in place during the whole snow season at the experimental site. Once a week, the snow collectors are checked in order to verify the occurrence of snowdrifting and whether there is evidence that a snowdrifting event has occurred; immediately afterwards, the snow collectors are emptied. The collected snow is weighed and the data provide the vertical mass-flux profiles from 0.26 to $1.65 \mathrm{~m}$.

The vertical distance between the inlets is $0.26 \mathrm{~m}$. The height of the inlet depends on the thickness of the snow, which is often difficult to determine. The distance between the top of the snow and the first inlet was measured weekly and when the collectors were emptied.

The snow-collector columns always remain in place at the experimental plot, which means that they accumulate a representative part of the total amount of snow drifted by the wind during a wind episode.

\section{Type A snow traps}

The snow traps consist of two aluminium poles each $2 \mathrm{~m}$ long, between which eight traps are fixed. These traps have a solid aluminium rectangular part, which fits into the poles, and a nylon bag attached to it. The pores in the bags are $0.110 \mathrm{~mm}$. The inlet area is $50 \mathrm{~cm}^{2}$ and the capacity of the bags is 21 . The trap's position is variable from 0 to $2 \mathrm{~m}$ above the snow surface (Fig. 1).

While snowdrifting occurs, the snow traps are situated in an open area in which transport is the main process. The flux, a mixture of air and snow grains, goes through the traps and while the snow is collected in the bag the air escapes through the pores.

\section{Type B snow traps}

Similar to the other types of trap, this gauge is also composed of two pieces, a metal structure and a nylon bag attached to each trap. The metal part of the trap has two cones and an elbow, and the nylon bags are attached to one of the cones while the other faces the wind. The pores in the nylon bags are $0.110 \mathrm{~mm}$. The minimal distance between one trap and the one above it is $0.25 \mathrm{~m}$, which limits the vertical mobility of the traps. We can use as many as four traps per profile (Fig. 1).

The lightness and mobility of these gauges, A and B, allow experimentation at any place. However, once the experiment was completed, a covered place was needed to empty and weigh the snow collected in the bags. The measurements made with the snow traps ranged over a period of 15 minutes to several hours, depending on the intensity of the drifting event.

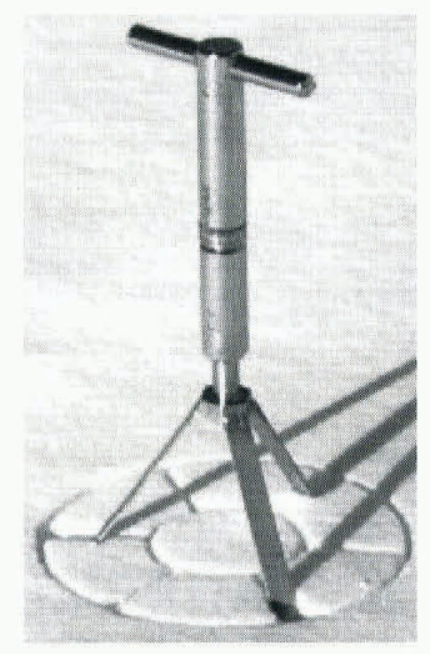

Fig. 2. The shear-stress device (Guily, 1991). 


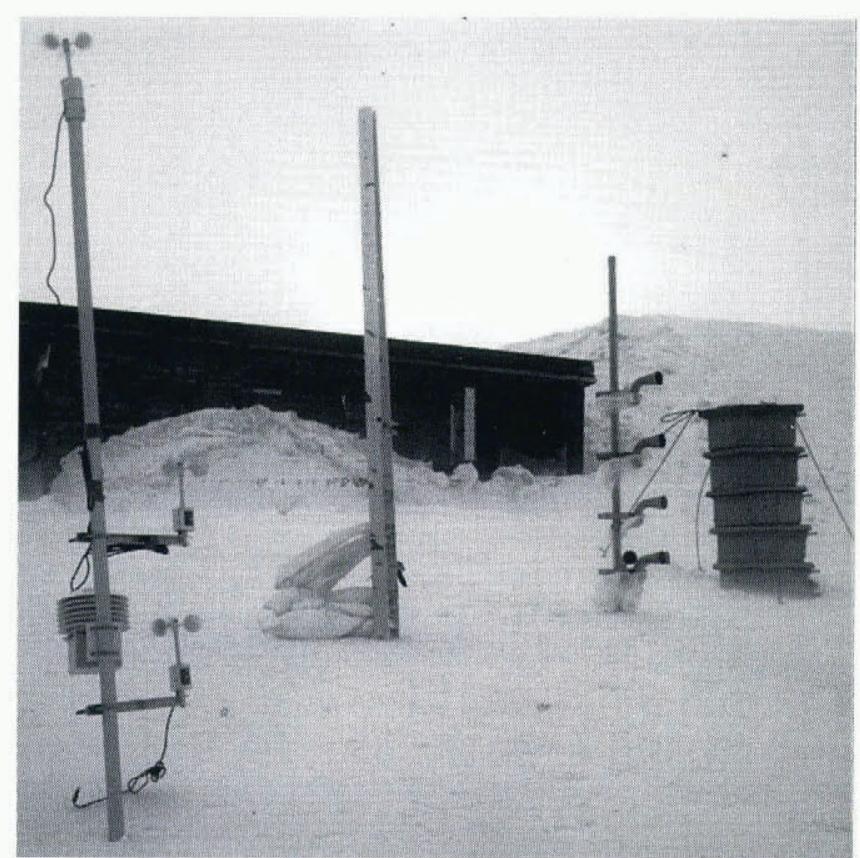

Fig. 3. The different gauges during a field experiment. From left to right: anemometers, snow trap $A$, snow trap $B$ and snow-collector column.

Using the snow traps, a vertical wind profile was obtained by using a column of three wind-speed sensors.

We also measured surface-snow hardness with a shearstress device that was designed and tested by the Centre d'Études de la Neige, Météo-France (Guily, 1991) (Fig. 2). The snow surface and air temperature were measured during the mass-flux measurements and the snow-grain sizes and shapes were also observed.

\section{COMPARISON OF GAUGES USED IN MASS-FLUX MEASUREMENTS AT LA MOLINA}

Since the 1992-93 season, different gauges have been progressively installed at the experimental plot.

In mass-flux measurements, the gauges used collect a quantity of snow representative of the natural phenomenon. The amount of snow collected is considered to be the minimal amount that drifts, since there is often a loss of drifted mass due to the trap's design.

Field tests have been carried out with the aim of establishing a relative collection efficiency value for each gauge and discovering which gauge is the most representative of the natural phenomenon.

We have situated the three gauges at the same places to ensure there are identical transport conditions to facilitate their comparison. In Figure 3, we show one of these field tests; the wind was blowing from right to left and the hut was situated behind (lee side) and to the right of the testing area. Results show important differences; the snow traps, both types A and B, collect similar quantities of snow, whereas the snow-collector columns collect much more. We consider the collector that collects the highest amount of snow is the most efficient; thus, the collection efficiency of this gauge is considered to be $100 \%$ for this episode.

In Table 1 we present the data obtained during the snowdrifting episodes of 8 February 1996 (columns a, b and c) and of 15 February 1997 (the remainder of the columns). For the first episode, we tested both types of snow trap, A and $\mathrm{B}$, and for the second the three gauges were tested.

From the observation of Figure 4 (Table 1), we assume that although wind velocities were similar during both episodes, from 20-22 $\mathrm{m} \mathrm{s}^{-1}$, transport values on the 8 February

Table 1. Data obtained from La Molina during the snowdrifting episodes of 8 February 1996 and 15 February 1997




1996 episode were lower than those of the 15 February 1997 episode. There is an influence of the snow-surface hardness that is 0.029 and $0.025 \mathrm{~kg} \mathrm{~cm}^{-2}$, respectively, but as these values are similar we consider that the main factor is the availability of snow to be drifted, 0.35 and $0.65 \mathrm{~m}$, respectively.

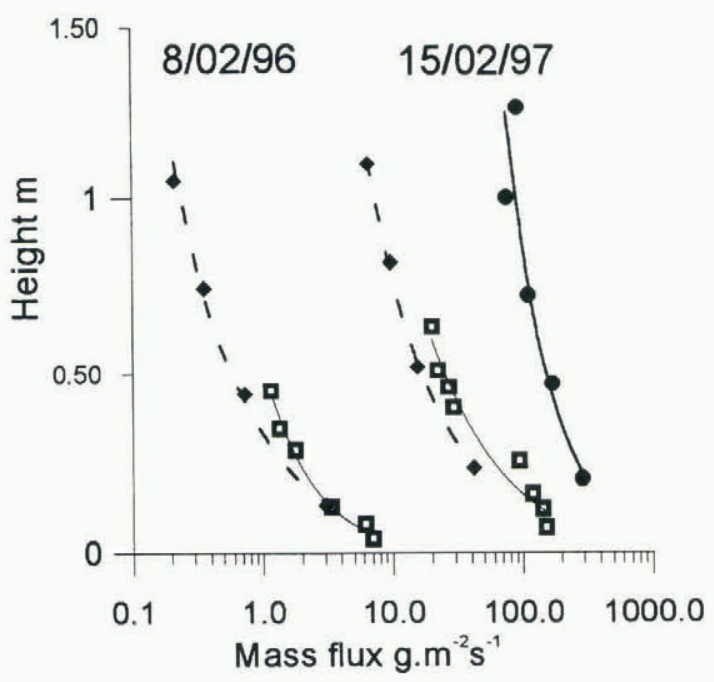

Fig. 4. Comparison of the mass-flux profiles obtained using the three different gauges used at La Molina. Lines are fitted to the data (see Table 1).

In column i of Table 1, we present the snow-collector column values for the 15 February 1997 episode. The higher mass-flux values were obtained from these columns. Considering these values to be $100 \%$, a relative efficiency rate for the different gauges at different heights was established. Results are shown in column $\mathrm{f}$ for type $\mathrm{A}$ snow traps and column h for type B snow traps (Table 1; Fig. 5).

In Figure 5, the variations of the relative collection-efficiency values with height above the surface are shown. We observed a decrease in the collection efficiency with height.

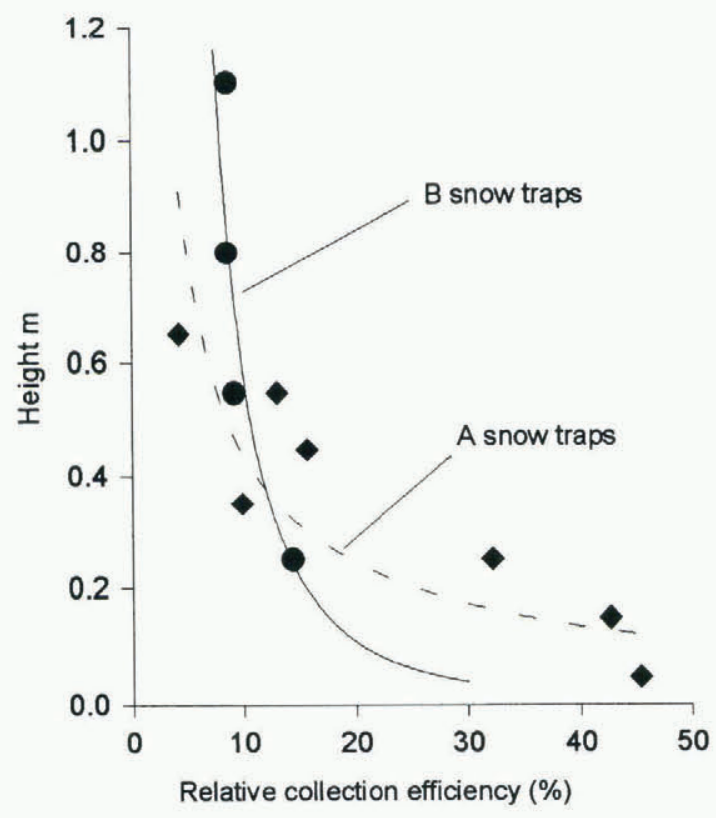

Fig. 5. Relation of the collection efficiency, relative to the snow-collector columns, with heights for the type $A$ and $B$ snow-trap gauges. Lines are fitted to the data (see Table 1).
The highest efficiency values of the snow traps are about $45 \%$ of the snow-collector columns.

Sato (1990) proposed that the sublimation rate increases with increases in air temperature and the transfer coefficient for sensible heat, which is close to that for water vapour. The sublimation rate was shown to decrease with an increase in relative humidity of the air. The transfer coefficient is an increasing function of ambient wind speed and does not depend on air temperature, humidity or the depth of the snow in the collector.

From measurements in a cold room with a net-type collector and a cyclone-type collector, Sato (1991) found that the error in the mass-flux measurement with the net-type collector, caused by the sublimation of the collected blowing snow, was below that for the cyclone-type collector.

Our snow traps are comparable to Sato's net-type collectors and the snow-collector columns are similar to Sato's cyclone-type collector. However, as the snow-collector columns are closed reservoirs, even if sublimation processes affect the snow collected, water vapour remains inside the collector and is also measured. In the snow traps, sublimation affects the measurements, because it produces a loss in the amount of snow mass collected. We can consider sublimation to be one of the causes of the differences found in the trapping efficiency among the three gauges.

Even if the experimental results show that the snow collector columns are the most efficient in representing the natural phenomenon, this gauge is not particularly useful for short-duration measurements and its design implies mobility difficulties. However, this gauge is very useful, because it remains in place during the whole of the snowdrifting episode and allows for quantification of the total amount of snow drifted away. Although the snow traps have a lower trapping efficiency rate, their lightness and mobility are considered to be of considerable usefulness and the design of their inlets permits short-duration experiments.

\section{COMPARISON OF LA MOLINA EXPERIMENTAL MASS-FLUX PROFILES}

We have selected nine mass-flux vertical profiles that are considered to be representative of mass-flux data collected at the La Molina experimental plot between 1992 and 1996. The three different gauges used are shown in Figure 6 and the main features of the snowdrifting events are summarized in Table 2 .

Table 2. Features of the profiles shown in Figure 6

\begin{tabular}{cccc}
\hline $\begin{array}{c}\text { Profile number } \\
\text { and date }\end{array}$ & $\begin{array}{c}\text { Wind } \\
\text { velocity } \\
m^{-1}\end{array}$ & $\begin{array}{c}\text { Snow } \\
\text { Hardness } \\
\mathrm{kg} \mathrm{cm}^{-2}\end{array}$ & \\
& & \\
\hline & & \\
\hline $1-15 / 02 / 97$ & 22 & 0.025 & Snow collector \\
$2-15 / 02 / 97$ & 22 & 0.025 & A snow traps \\
$3-15 / 02 / 97$ & 22 & 0.025 & B snow traps \\
$4-15 / 02 / 97$ & 20 & 0.03 & B snow traps \\
$5-16 / 02 / 96$ & 28 & 0.046 & A snow traps \\
$6-25 / 04 / 95$ & 13 & 0.025 & A snow traps \\
$7-25 / 04 / 95$ & 13 & 0.025 & A snow traps \\
$8-16 / 02 / 96$ & 22 & 0.046 & A snow traps \\
$9-13 / 12 / 95$ & 18 & 0.042 & A snow traps \\
& & & \\
\hline
\end{tabular}


From observation of the different profiles, each of the three gauges represent equally the main features of the snowdrifting events, although different gauges have different trapping-efficiency values. Profiles of the same snowdrifting event have similar slopes. Differences are in the relative position of the profiles; some of these can be explained by the trapping efficiency of the gauges. This is reflected in profiles 1, 2, 3 and 4 of Figure 6.

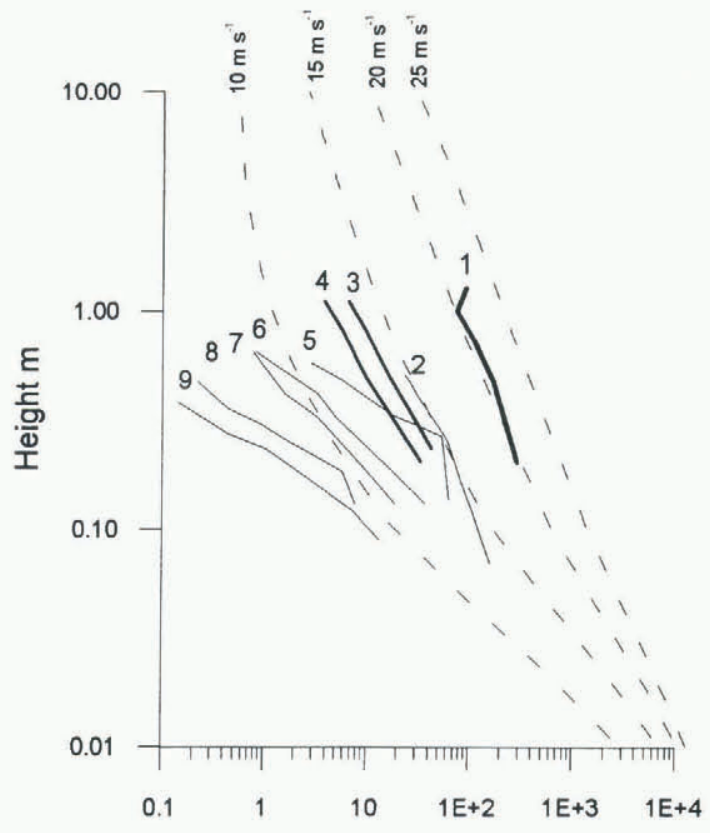

Mass flux $\mathrm{g} \mathrm{m}^{-2} \mathrm{~s}^{-1}$

Fig. 6. Experimental mass-flux profiles vs height obtained at La Molina. Using the type A snow trap profiles: 2, 5, 6, 7, 8 and 9, together with the $B$ snow traps 3 and 4 and profile 1 with the snow-collector columns. Dashed lines represent the theoretical values proposed by Mellor and Fellers (1986) (see Table 2).

Profile 1, which represents the highest mass-flux values, its from data obtained using the snow-collector columns. Profile 2 is obtained using type A snow traps and profiles 3 and 4 using type B snow traps. Although profiles 3 and 4 were obtained using the same gauge, profile 3 was obtained at the beginning of the snowdrifting event and is characterized by a snow-surface hardness and wind-speed relation that eases snowdrifting. The measurements of profile 4 show that this relation is not as favourable to snowdrifting, which explains some of the differences found in the mass-flux values.

Even if profiles 5, 8 and 9 pertain to different snowdrifting events, 16 February 1996 (5, 8) and 13 February 1995 (9), the slopes are very similar. We assume that this similarity comes from the snow-surface hardness values that are very high in the three cases: $0.046,0.046$ and $0.042 \mathrm{~kg} \mathrm{~cm}^{-2}$, respectively. Although profiles 5 and 8 have higher snow-surface hardness, mass-flux values are higher than in profile 9 , and this is due to wind velocity which is higher in the first two profiles.

Finally, profiles 6 and 7 represent snowdrifting events characterized by light winds $\left(13 \mathrm{~m} \mathrm{~s}^{-1}\right)$. The relative positions of the two profiles is explained by differences in time during the same snowdrifting event. In this case, we consid- er that the availability of snow to be drifted controls the mass-flux values of these profiles (Table 2).

The relation of snow-surface hardness to wind velocity is one of the main factors controlling mass flux during a snowdrifting event.

We have compared our experimental profiles with those fitted by Mellor and Fellers (1986) for experimental data obtained in Antarctica (Fig. 6). Mellor and Fellers (1986) fitted a regression equation relating mass flux to wind speed and height above the surface; it provides reasonable estimates for snow transport up to a height of $5 \mathrm{~m}$. This relationship can be used to estimate the quantity, direction and vertical distribution of seasonal-snow transport from wind records (Tabler, 1991).

Mellor and Fellers (1986) derived the following regression equation relating mass flux $q\left(\mathrm{~g} \mathrm{~m}^{-2} \mathrm{~s}\right)$ to height $z(\mathrm{~m})$ and wind speed $U_{10}\left(\mathrm{~m} \mathrm{~s}^{-1}\right)$ :

$$
\begin{aligned}
\ln q= & 10.089-0.41049 x_{1}-122.03 x_{2}-0.13856 x_{1}^{2} \\
& -14.446 x_{1} x_{2}-0.0059773 x_{1}^{3}+3.2682 x_{1}^{2} x_{2} \\
& +114.13 x_{1} x_{2}^{2}+2290.0 x_{2}^{3}
\end{aligned}
$$

where $x_{1}=\ln z$, and $x_{2}=1 / U_{10}$. The correlation coefficient $R^{2}=0.978$.

The dashed lines in Figure 6 represent the fitted values for each wind velocity. The only profile that fits with Mellor and Fellers' values is profile 1. These data were obtained with snow-collector columns; thus, we assume that these collectors are most similar to the Mellor drift traps.

Finally, we have corrected the values of the A and B snow traps, applying the collection-efficiency rates, and compared them with the suggested profiles of Mellor and Fellers (1986) (Fig. 7). Profiles 5, 8 and 9 do not fit with the

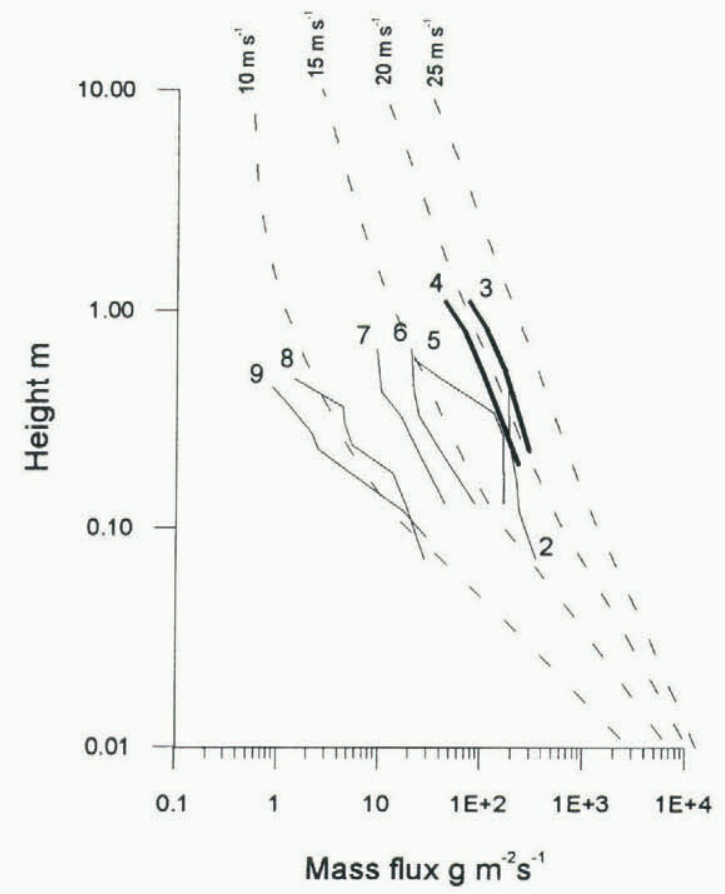

Fig. 7. Experimental mass-flux profiles vs height obtained at La Molina. The values of the A (profiles 2, 5, 6, 7, 8 and 9) and $B$ (profiles 3 and 4) traps have been corrected applying the collection efficiency rates obtained from the comparison with the snow-collector columns. Dashed lines represent the theoretical values proposed by Mellor and Fellers (1986) (see Table 2). 
theoretical ones and we assume that this is because the snow-surface hardness values were too high to reach flux saturation in these three episodes. The remainder of the profiles fit well after the trapping-efficiency correction has been done.

\section{CONCLUSIONS}

The gauges designed to quantify aeolian-transport processes collect a representative amount of the natural phenomenon. We consider the gauge that collects the highest quantities of snow is the most representative.

By comparing data obtained at La Molina with three different gauges (snow traps $\mathrm{A}$ and $\mathrm{B}$ and the snow-collector columns), the important role of gauge design is confirmed. The snow-collector columns are the most efficient, so we have considered this gauge as $100 \%$ for the episode. The snow traps relative efficiency is below $45 \%$ of the snow-collector columns efficiency.

The snow-collector columns were designed to remain fixed in the field; thus, they contained the total amount of drifted snow for a drifting-snow event. The snow traps (types A and B), even if less efficient than the snow-collector columns, are useful for short-duration measurements, because of their mobility and lightness.

We compared our experimental profiles with those calculated using the regression of Mellor and Fellers (1986) for experimental data obtained in Antarctica and observed that our experimental values were below the calculated ones. However, the type of gauge used could explain this discrepancy. Mellor and Feller's traps efficiency is more similar to our snow-collector columns than to our own snow traps.

Indeed, after correcting the snow-trap data in relation to the snow-collector column, we observe that our field data fit with the proposed values of Mellor and Fellers (1986).

\section{ACKNOWLEDGEMENTS}

This research was funded by Project AMB-0837 from the CICYT and Project of Human Capital and Mobility of the ECC, contract No. CHRX-CT93-0307 ( DG COMA ). The authors thankJ. Dent and two anonymous reviewers for critically reviewing previous versions of this manuscript.

We should also like to thank La Molina (Ferrocarrils de la Generalitat de Catalunya) ski resort for the logistic support given and especially the ski-patrol team.

\section{REFERENGES}

Bagnold, R. A. 1941. The physics of blowing sand and desert dunes. London, Methuen.

Guily, L. 1991. L'exploitation technique des pistes de ski alpin dans le domaine skiable français. (Thèse de doctorat d'état, Université Joseph Fourier - Grenoble I.)

Mases, M. and J. M. Vilaplana. 1994. Estudio del transporte é́lico de la nieve en el Pirineo Oriental: primeros resultados. In Arnáez, J., J. M. García-Ruíz and A. Gómez Villar, eds. Geomorfología en España. Logroño, Sociedad Española de Geomorfología, 209-225.

Mellor, M. and G. Fellers. 1986. Concentration and flux of wind-blown snow. CRREL Spec. Rep. 86-11.

Naaim-Bouvet, F., M. Naaim and H. Martinez. 1996. Profils de concentration de la neige soufflée: théorie, résolution et validation expérimentale in situ. Houille Blanche, 51 (5), 53-57.

Salvador, F. 1985. Aportación al estudio nivoclimático del Pirineo Oriental. Notas de Geografía Física 13-14, 67-84.

Sato, T. 1990. [Sublimation rate of collected blowing snow in a cyclone type collector.] Seppyo, 7. Jpn. Soc. Snow Ice, 52(2), 91-98. [In Japanese with English summary.]

Sato, T. 1991. [Sublimation rate of collected blowing snow in a net type collector.] Seppyo, 7. Jpn. Soc. Snow Ice, 53 (2), 135-143. [InJapanese with English summary.]

Tabler, R. D. 1991. Snow transport as a function of wind speed and height. In Sodhi, D. S., ed. Cold Regions Engineering. Proceedings of the Sixth International Specialty Conference ..., West Lebanon, NH, February 26-28, 1991. New York, American Society of Civil Engineers, 729-738.

Takeuchi, M. 1980. Vertical profile and horizontal increase of drift-snow transport. f. Glaciol., 26(94), 481-492. 